\title{
THE QUANTITATIVE DETERMINATION OF AMINO-ACIDS IN URINE USED IN CONJUNCTION WITH ONE-DIMENSIONAL PAPER CHROMATOGRAPHY
}

\author{
BY \\ D. C. SMITH AND S. L. TOMPSETT \\ From the Biochemical Laboratory, Northern General Hospital, Edinburgh
}

(RECEIVED FOR PUBLICATION AUGUST 26, 1953)

The value of paper chromatography in the study of the amino-acids of urine in disease has been shown in particular by Dent $(1946,1948)$. Although present methods of one- or two-dimensional paper chromatography can indicate important quantitative changes to the observer, there is some difficulty in conveying impressions to another, e.g., to a clinician or to a reader of a paper. It does appear that a reasonably simple quantitative approach to the subject would be an advantage so that the progress of a case of variable rates of excretion by, say, the right and left kidneys, can be represented readily on paper. The following technique appears in part to fulfil this function and has been used in this laboratory for some months.

One-dimensional paper chromatography has been used. Although there is overlapping of certain of the amino-acids, it has been proved more convenient for day-to-day observations in the clinical laboratory. More specific information can naturally be obtained if necessary by the use of two-dimensional paper chromatography. "Runs" are made in the "kawerau" unit (1951). This has proved of great convenience since an incubator can house several of these units, a constant temperature being thereby maintained. The solvent used is n-butanol/acetic acid. Amino-acid nitrogen is determined quantitatively by a modification of the colorimetric ninhydrin procedure of Smith and Agiza (1951). The following represents the main departure from the usual procedure. Instead of locating individual amino-acids by their $\mathbf{R}_{\mathbf{F}}$ values the paper is divided into 10 strips corresponding to $R_{F} 0.0-0.1,0.1-0.2 \ldots \ldots$ $0.8-0.9,0.9-1.0$ and the amino-acid nitrogen content of each strip determined. The results are then plotted in the form of a graph, mg. aminonitrogen per $100 \mathrm{ml}$. against $R_{F}$. This allows of ready comparison. Undoubtedly some amino- acids will make their appearance on adjacent strips.

\section{Procedure}

Apparatus.-The following is required.

(1) Kawerau unit (Quickfit and Quartz Ltd.) maintained in an incubator at $37^{\circ} \mathrm{C}$.

For the solvent, $40 \mathrm{ml}$. of n-butanol, $10 \mathrm{ml}$. of glacial acetic acid, and $50 \mathrm{ml}$. of distilled water are shaken in a separating funnel. The non-aqueous phase is placed in one flask and the aqueous phase in the other. Since some esterification may occur with a consequent change in $R_{F}$, frequent changes of the solvent are advisable.

(2) Shandon micro-capillary pipettes.

(3) Whatman filter paper, No. 1, in strips of $20 \mathrm{~mm}$. width.

(4) Unicam spectrophotometer, G.P. 350.

Reagents.-The following should be made up:

Citrate Buffer pH 5.-Citric acid, 21.008 g., is dissolved in $200 \mathrm{ml}$. of water $\left(\mathrm{C}_{6} \mathrm{H}_{8} \mathrm{O}_{7} . \mathrm{H}_{2} \mathrm{O}\right), 200 \mathrm{ml}$. of $\mathrm{N}$ sodium hydroxide added and diluted to $500 \mathrm{ml}$. with water.

Ninhydrin Reagent.-Ninhydrin, $550 \mathrm{mg}$., is dissolved in $100 \mathrm{ml}$. of citrate buffer.

Stannous Chloride Reagent.-Stannous chloride, $0.1 \mathrm{~g}$., is dissolved in $50 \mathrm{ml}$. of citrate buffer. This reagent must be prepared freshly.

Technique.-Urine, $20 \mu \mathrm{l}$., measured by means of a "shandon" micro-capillary pipette, is placed just in front of a pencil line drawn across the filter paper strip. After drying the paper is arranged in the apparatus so that the end nearest the pencil line dips into the organic solvent mixture. The apparatus is placed in an incubator at $37^{\circ} \mathrm{C}$. for 24 hours. At the end of this period the paper is removed, the position of the solvent front marked with a pencil line, and then allowed to dry at room temperature.

The paper between the two pencil marks (approximate length $30 \mathrm{~cm}$.) is divided into 10 equal parts, corresponding to $R_{F}$ ranges $0.0-0.1,0.1-0.2 \ldots \ldots$. 0.9-1.0. Each strip is placed in a separate test-tube and $5 \mathrm{ml}$. of water, $2 \mathrm{ml}$. citrate buffer. $2 \mathrm{ml}$. nin- 

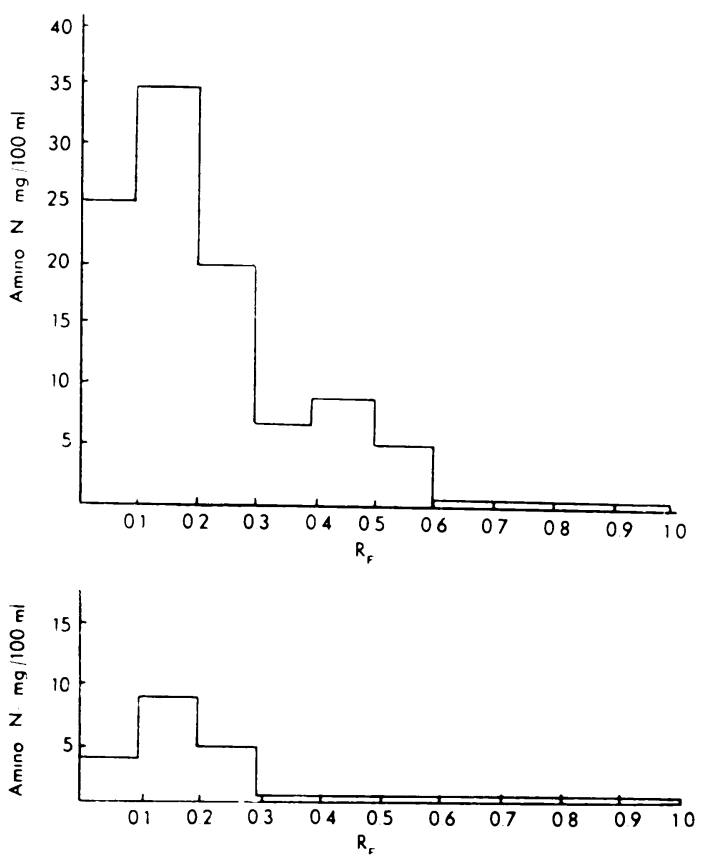

FIG. 1.-Graph of a case of liver damage. Above : on admission, amino- $\mathrm{N}$ was $96 \mathrm{mg}$. $100 \mathrm{ml}$., and on discharge (below) it was $14.5 \mathrm{mg} .100 \mathrm{ml}$.

hydrin reagent, and $1 \mathrm{ml}$. stannous chloride reagent added in order.

The tubes are placed in a boiling water-bath for 15 minutes and then cooled in cold water in the dark. The absorption of the purple colour which results is then measured in any suitable absorptiometer at $570 \mathrm{~m} \mu$. against tube No. $10\left(R_{F} 0.9-1.0\right)$.

Results are read off a graph prepared from a standard solution of glycine (1-5 $\mu \mathrm{g}$. amino $\mathrm{N} / 5 \mathrm{ml}$.).

The positions occupied by the various amino-acids on the strips can be determined by submitting solutions of the pure substances to the above treatment.
The attached figure represents the method of recording the results. These are from a case of liver disease on admission and on discharge.

\section{Discussion}

Tube No. 10 has been used as the blank since none of the known amino-acids have $R_{F}$ values approaching this value when the above solvent system is used.

Equivalent amounts of different amino-acids do not give the same depth of colour with the ninhydrin reaction, the depths varying from $100 \%$ for glycine, leucine, iso-leucine, and nor-leucine to $79 \%$ for cystine (Smith and Agiza, 1951). Corrections have not been applied, since, in this type of examination, it would be most difficult, and, in any case, clinical interpretations would hardly be affected.

When warranted, it has been possible to apply more specific colour reactions to the strips suspended in water for the quantitative determination of certain amino-acids, e.g., the Pauly reaction (histidine, histamine), the phenol reagent (tyrosine, tyramine). Although the phenol reagent itself is non-specific in the above solvent system, the usual urinary phenols have $\mathbf{R}_{\mathbf{F}}$ values much higher than tyrosine or tyramine.

\section{Summary}

A procedure for the quantitative determination of amino-acids in urine by means of the ninhydrin reaction after one-dimensional paper chromatography has been described.

\section{REFERENCES}

Dent, C. E. (1946). Lancet, 2, 637.

(1948). Biochem. J., 43, 169.

Kawerau, E. (1951). Ibid., 48, 281.

Smith, A. M., and Agiza, A. H. (1951). Analyst, 76, 623. 